\title{
Midlatency auditory evoked potentials do not allow the prediction of recovery from general anesthesia with isoflurane
}

\author{
[Les potentiels éroqués auditifs de milatence ne permettent pas de prédire la \\ récupération après une anesthésie générale à l'isoflurane]
}

Ingrid Rundshagen MD, ${ }^{\star}$ Kai Schnabel, $†$ Jochen Schulte am Esch MD

\begin{abstract}
Purpose: To investigate midlatency auditory evoked potentials (MLAEP) waveforms during recovery from anesthesia. The hypothesis was that MLAEP are sensitive variables to discriminate between states of consciousness and unconsciousness during emergence from anesthesia.
\end{abstract}

Methods: MLAEP were recorded in the awake state and during the wake-up phase from isoflurane anesthesia in 22 female patients undergoing ophthalmologic surgery. During emergence from anesthesia the changes in latency and amplitude of MLAEP components $\mathrm{Na}, \mathrm{Pa}$ and $\mathrm{Nb}$ were compared with the awake level. The next day the patients were asked for explicit memory for the recovery period.

Results: In 72\% of the patients the MLAEP waveforms were completely suppressed during isoflurane anesthesia. When the patients responded and opened their eyes spontaneously $38 \pm 12$ min after anesthesia, the latencies of $\mathrm{Na}(18.3 \pm 1.2$ vs $17.6 \pm 1.3 ; P=$ $0.013)$ and $\mathrm{Nb}(47.4$ vs 7.1 vs $44.7 \pm 7.8 ; P=0.048)$ remained prolonged compared with awake values. In contrast, the amplitudes $\mathrm{NaPa}$ and $\mathrm{PaNb}$ had regained baseline level. Nine patients had explicit memory for the immediate recovery period. However, there was no difference for any MLAEP component between patients with and without memory at any time.

Conclusions: The persistent changes of MLAEP latency components $\mathrm{Na}$ and $\mathrm{Nb}$ indicated impaired auditory signal processing 38 min after isoflurane anesthesia. There was a marked intra- and interindividual variability during reversal of the anesthetic induced MLAEP changes. This limits the prediction of recovery of consciousness in the individual patient during emergence from anesthesia.
Objectif : Examiner les tracés des potentiels évoqués auditifs de milantence (PEAML) pendant la récupération de l'anesthésie. L'hypothèse était que les PEAML sont des variables sensibles qui permettent de distinguer les états de conscience et d'inconscience pendant le réveil postanesthésie.

Méthode : Les PEAML ont été enregistrés à l'état vigil et pendant le réveil postanesthésie à l'isoflurane chez 22 femmes en chirurgie ophtalmologique. Pendant le retour à la conscience, les modifications du temps de latence et de l'amplitude des composantes $\mathrm{Na}$, Pa et $\mathrm{Nb}$ des PEAML ont été comparées avec celles de l'état vigil. Le jour suivant, on a interrogé les patientes sur le souvenir qu'elles avaient de la période de récupération.

Résultats : Chez $72 \%$ des patientes, les tracés des PEAML ont été complètement supprimés pendant l'anesthésie à l'isoflurane. Quand les patientes ont repris conscience et ont ouvert les yeux spontanément, $38 \pm 12$ min après l'anesthésie, les temps de latence de $\mathrm{Na}$ ( I8,3 $\pm 1,2$ vs 17,6 $\pm 1,3 ; P=0,013)$ et de $\mathrm{Nb}(47,4$ vs 7, I vs $44,7 \pm 7,8 ; P=0,048)$ sont demeurés longs comparés aux valeurs vigiles. Par ailleurs, les amplitudes $\mathrm{NaPa}$ et PaNb ont repris les valeurs de base. Neuf patientes ont eu un souvenir explicite de la période de récupération immédiate. Cependant, il n'y a pas eu de différence interpatientes concernant l'une ou l'autre composante des PEAML, sans égard à la présence ou non de souvenir.

Conclusion : Les changements persistants des composantes $\mathrm{Na}$ et $\mathrm{Nb}$ des temps de latence des PEAML ont indiqué une modification du traitement du signal auditif 38 min après l'anesthésie à l'isoflurane. II y a eu une variabilité intra-individuelle et interindividuelle marquée pendant le renversement des changements des PEAML induits par l'anesthésie. Ce résultat limite les possibilités de prédire le retour à la conscience pendant le réveil postanesthésie.

From the Department of Anesthesiology, ${ }^{*}$ University Hospital Charité, Humboldt University of Berlin, Campus Charité Mitte, Berlin, Germany; the Department of Psychology, $†$ University of Michigan, Ann Arbor, USA; and the Department of Anesthesiology, $\ddagger$ UniversityHospital Eppendorf, Hamburg, Germany. Address correspondence to: Dr. Ingrid Rundshagen, Department of Anesthesiology, University Hospital Charité, Campus Charité Mitte, Schumannstr. 20/21, D-10117 Berlin, Germany. Phone: 49-30-450 531 012; Fax: 49-30-450 531911 ;

E-mail: ingrid.rundshagen@charite.de Accepted for publication July 3, 2001

Revision accepted January 16, 2002. 
$M$ OST of the anesthetics used during general anesthesia alter the functional state of the central nervous system (CNS). However, in routine clinical practice the CNS is not monitored. The anesthesiologist usually relies on autonomic variables such as blood pressure, heart rate, pupillary reactivity, lacrimation and/or muscle responses to estimate depth and quality of anesthesia. For clinical routine and for scientific questions there is a need to evaluate variables, which might be useful to quantify and to objectify different functional states of the CNS during general anesthesia. Quantification of the pharmacodynamic characteristics of anesthetic agents is necessary to avoid over- or undermedication and potential risks to the patients. ${ }^{1,2}$

Several studies have been carried out to define the anesthetic action of drugs on the CNS using different variables of the spontaneous or evoked electroencephalogram (EEG). ${ }^{3,4}$ While the EEG provides information on the actual functional state of the brain, the evoked responses indicate stimulus induced changes of the neural pathway from the receptor at the peripheral site all the way to the specific projection areas in the brain. It has been shown that the different components of the evoked responses are generated in specific areas of the brain. However, the exact location of some components is still debated. ${ }^{4}$ Several recent studies indicate that the midlatency auditory evoked potentials (MLAEP) are a promising tool to quantify the hypnotic component during anesthesia. ${ }^{5}$

In 1989, Thornton and colleagues could demonstrate in seven patients, anesthetized with thiopentone and nitrous oxide after premedication with morphine, that the midlatency AEP component $\mathrm{Nb}$ could differentiate, with a $100 \%$ specificity, whether patients would follow a command using the isolated forearm technique. ${ }^{6}$ They suggested that a threshold of $44.5 \mathrm{msec}$ for the $\mathrm{Nb}$ latency could be used as a possible indicator for intra-operative awareness. In addition to some other investigations supporting this finding, Davies et al. could demonstrate in patients, sedated with propofol during regional anesthesia, that the changes of the $\mathrm{Nb}$ latency were the most sensitive variable to differentiate between loss and return of consciousness. ${ }^{7}$

The present study investigated MLAEP during emergence from isoflurane anesthesia in comparison to the awake state. We tested the hypothesis that the MLAEP latencies correlate with a decreasing level of sedation and discriminate states of consciousness and unconsciousness during recovery from anesthesia.

\section{Methods}

After obtaining approval from the local Ethics Committee and written informed consent, 22 patients, scheduled for elective ophthalmological surgery, were included in this prospective study. Patients with neurological diseases or hearing abnormalities were excluded. The patients did not take any centrally acting drugs.

\section{Anesthesia and recovery}

All patients received midazolam $7.5 \mathrm{mg}$ orally as a premedication $45 \mathrm{~min}$ prior to anesthesia. Anesthesia was induced with propofol $2 \mathrm{mg} \cdot \mathrm{kg}^{-1}$, sufentanil 0.4 $\mu \mathrm{g} \cdot \mathrm{kg}^{-1}$ and vecuronium $0.1 \mathrm{mg} \cdot \mathrm{kg}^{-1}$. Endotracheal intubation was performed and anesthesia maintained with isoflurane $0.6 \%$ (end-tidal) in nitrous oxide and oxygen (30\%). An additional bolus of sufentanil 0.25 $\mu \mathrm{g} \cdot \mathrm{kg}^{-1}$ was administered if necessary. Approximately $20 \mathrm{~min}$ before the end of surgery nitrous oxide was stopped and anesthesia maintained with $1.2 \%$ isoflurane. After the end of surgery and after the MLAEP had been recorded under anesthesia, the administration of isoflurane was stopped, $100 \%$ oxygen was delivered (fresh gas flow $3 \mathrm{~L} \cdot \mathrm{min}^{-1}$ ), and the patients allowed to recover. After extubation patients received oxygen via a face mask.

\section{AEP-data acquisition}

The day before surgery patients were familiarized with the procedure of MLAEP recording in order to obtain awake baseline values. MLAEP recording was performed in a standardized manner with an Evomatic $4000{ }^{\circledR}$ system (Dantec, Copenhagen, Denmark). The individual hearing threshold was defined. The stimulus intensity was about $70 \mathrm{~dB}$ above the individual threshold and kept constant throughout the whole study. Baseline recording was replicated twice. An $8 \mathrm{~Hz}$ stimulus frequency was applied using binaural randomized click stimulation via headphone. The MLAEP waveforms were recorded on two amplifier channels using zinc/lead cup electrodes placed over $\mathrm{Cz}$ (international 10-20 system) and bilateral mastoid. Electrode impedances were kept below $5 \mathrm{k}$. A poststimulus period of 90 msec was analyzed. During anesthesia and recovery a period of $180 \mathrm{msec}$ was recorded. The brainstem component $\mathrm{V}$ served as a reference that the auditory stimulus was delivered correctly. Moreover, the device included an automatic artefact rejection mode. Using a bandpass 0.02 to $2 \mathrm{k} \mathrm{Hz}$ for each response 2000 stimuli were averaged and stored on disk for later analysis. Latencies and peak-to-peak amplitudes were obtained using a software package (EvoPC®, Müller, Hamburg, Germany). The following peak latencies were obtained: 
brainstem component $\mathrm{V}$, two negative components $(\mathrm{Na}, \mathrm{Nb})$ and one positive peak in between $(\mathrm{Pa})$. The peak-to-peak amplitudes $\mathrm{NaPa}$ and $\mathrm{PaNb}$ were measured. When patients presented a postauricular reflex (PAR), the latency and amplitude were determined (LatPAR, AmpPAR).

\section{Measurements}

MLAEP recording started on the day before surgery in order to obtain baseline data in the awake state (AWAKE). Then, the MLAEP recording was performed on the day of surgery during steady state isoflurane anesthesia after the end of surgery (ANESTH), and every five to ten minutes during recovery from anesthesia. In accordance with the clinical findings, Pre-EXT was defined as the last MLAEP recording before extubation and Post-EXT as the first recording following extubation, when the patients opened their eyes on command. When the patients opened their eyes spontaneously, they were asked to verbally define a shown object (a small red booklet [about $12 \times 15 \mathrm{~cm}$ in size], which was opened and closed in front of the patient). The final MLAEP recording was performed (RECOVERY), when they correctly named the object shown.

\section{Clinical variables}

Heart rate (beats. $\mathrm{min}^{-1}$ ), non-invasive mean arterial blood pressure $(\mathrm{mmHg})$, percutaneous oxygen saturation (\%) and body temperature were recorded in parallel to the MLAEP recording. During and after anesthesia end tidal carbon dioxide $\left(\mathrm{p}_{\mathrm{et}} \mathrm{CO}_{2}\right)$ and isoflurane $\left(\mathrm{p}_{\mathrm{et}} \mathrm{ISO}\right)$ concentrations were measured (via the endotracheal tube; after extubation, via a tightly held facial mask). In addition, the total duration of anesthesia, the time of the extubation and of RECOVERY were recorded. The day after the operation the patients were asked (structured interview), whether they recalled anything during anesthesia or the wake-up phase.

\section{Statistics}

Latencies and peak-to-peak amplitudes $\mathrm{NaPa}$ and $\mathrm{PaNb}$ were calculated. The sample distributions of data were checked with Kolmogorov-Smirnov tests. The MLAEP data were analyzed using multivariate analysis of variance (Hotellings T-square; repeated measurement design) provided the data were normally distributed. This statistical approach is most appropriate for studies involving repeated measurements with the same individuals. However it is applicable only to a data set in which all measurements have been made at all time points. ${ }^{8}$ Since in some patients the MLAEP waves completely disappeared during anes- thesia, only measurements at AWAKE, Pre-EXT, PostEXT and RECOVERY were included in the overall multivariate analysis resulting in a full two-factor-within design ( 3 latencies $\times 4$ time points). For descriptive purposes, a posteriori paired $t$ tests including all measurements were performed comparing each single MLAEP component at the different measurement points. When normal distribution was violated, nonparametric tests were used (Friedman test). Correlation coefficients were tested for the MLAEP components, the vital and clinical parameters. $P<$ 0.05 was adopted to determine significance. Prediction probability $\mathrm{P}_{\mathrm{K}}$ according to the method of Smith was calculated. ${ }^{9}$

\section{Results}

\section{AEP-parameter}

The mean stimulation intensity was $105 \pm 5 \mathrm{~dB}$. During the awake state the brainstem component V was identified in all patients. While 13 patients had a small or no postauricular reflex $(\mathrm{PAR}<2 \mu \mathrm{V})$, in seven patients it was larger. Figure 1 depicts the original MLAEP recordings of patients at AWAKE indicating the typical midlatency components. Following the postauricular reflex, two negative and one positive deflections of MLAEP components were clearly identified. However, there was one patient who did not present the component $\mathrm{Nb}$. An example of the

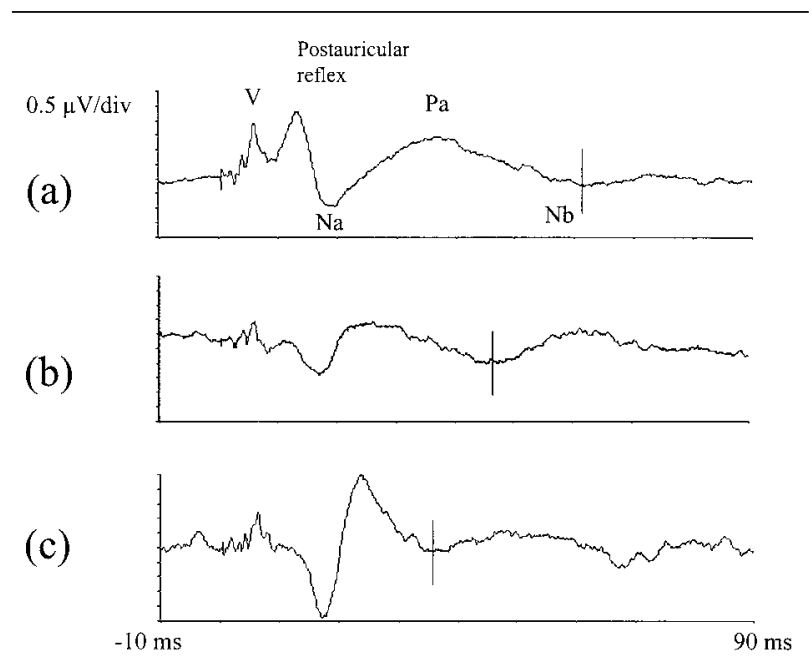

FIGURE I The original auditory evoked potential (AEP) tracings of three different patients in the awake state are shown. The postauricular reflex, the brain stem component $\mathrm{V}$ and the three midlatency components are indicated. (a) Patient SK, $25 \mathrm{yr}$, male; (b) patient FH, $42 \mathrm{yr}$, male; (c) patient $\mathrm{SU}, 33 \mathrm{yr}$, male. Vertical lines indicate the $\mathrm{Nb}$ latencies to show the inter-individual variability. Montage: $\mathrm{Cz}$ vs linked mastoid, binaural click stimulation. 


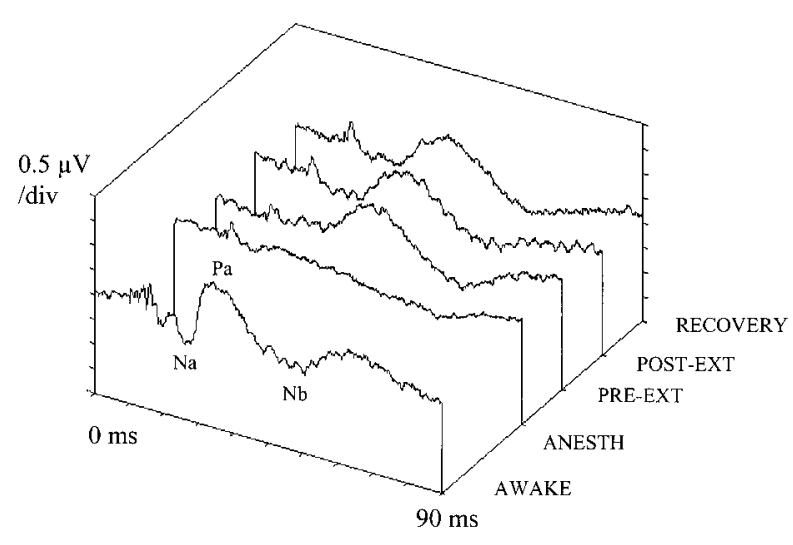

FIGURE 2 The original auditory evoked potential (AEP) tracings of patient $\mathrm{FH}, 42 \mathrm{yr}$, male, are shown during the different measurements. AWAKE $=$ the day before anesthesia; ANESTH $=$ after the end of surgery at $1 \mathrm{MAC}$ isoflurane; PRE-EXT = before extubation; POST-EXT = after extubation, when the patients opened their eyes at command; RECOVERY $=$ when the patients opened their eyes spontaneously. Montage: $\mathrm{Cz} v$ s linked mastoid, binaural click stimulation.

MLAEP changes during the various stages of measurements is given in Figure 2.

The Kolmogorov-Smirnoff test supported the assumption of normal distribution for all MLAEP latencies. In contrast, the amplitude $\mathrm{NaPa}$ was not normally distributed, therefore the amplitudes were analyzed by non parametric tests (Friedman test, Wilcoxon test). The multivariate analysis revealed an overall significant difference for the latency components comparing the different measurements $(P=$ 0.005) The absolute values of the MLAEP latencies are given in Table I. The Friedman test revealed significant changes for the amplitudes $\mathrm{NaPa}(P<0.001)$. The absolute values are documented in Table II. However, the data at ANESTH were excluded from testing, because, in 16 patients, the MLAEP components were suppressed completely.

During anesthesia with $1.2 \%$ isoflurane the brainstem component $\mathrm{V}$ was identifiable in all patients, the PAR was absent except in one patient. The MLAEP components were completely suppressed in 16 patients. In the other six patients the latencies $\mathrm{Na}$ and $\mathrm{Nb}$ were significantly prolonged in comparison to AWAKE $(P \leq 0.03)$.

During emergence the anesthetic-induced MLAEP changes were in part reversed. The last measurement before extubation (Pre-EXT), when the patients still tolerated the endotracheal tube and did not respond to

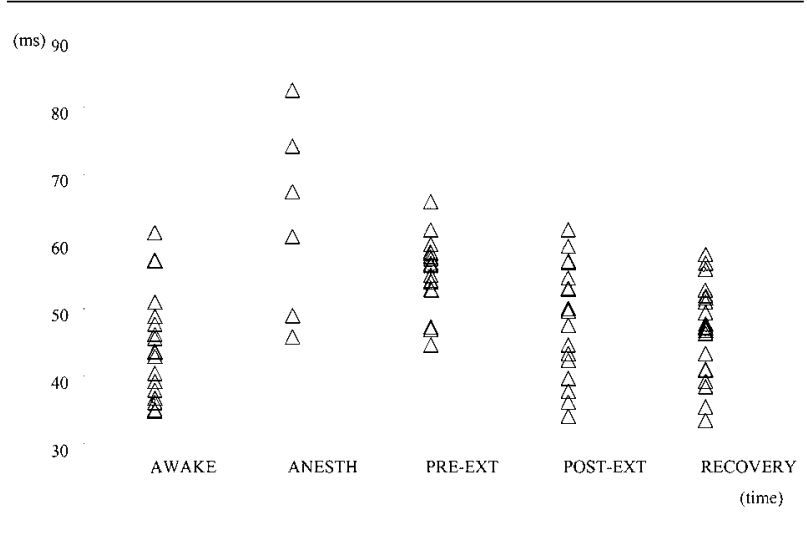

FIGURE 3 The individual responses of the midlatency auditory evoked potential (MLAEP) latency component $\mathrm{Nb}$ are shown during the different measurements. AWAKE = the day before anesthesia; $\mathrm{ANESTH}=$ after the end of surgery at 1 MAC isoflurane; PRE-EXT = before extubation; POST-EXT $=$ after extubation, when the patients opened their eyes at command; RECOVERY = when the patients opened their eyes spontaneously.

command, indicated MLAEP deflections in 20 patients. The latencies were still significantly prolonged $(P<0.03)$ and the amplitudes $\mathrm{NaPa}(P<0.001)$ reduced in comparison to AWAKE. The PAR recovered in 19 patients, but was smaller than $1 \mu \mathrm{V}$ except in one patient.

Immediately after extubation (Post-EXT), when the patients opened their eyes on command, the decrease in latencies and the increase in amplitudes was progressive in comparison to ANESTH. The latency Na was still significantly prolonged $(P=0.025)$, while the components $\mathrm{Pa}$ and $\mathrm{Nb}$ did not differ in latency from the baseline values. The amplitudes $\mathrm{NaPa}$ and $\mathrm{PaNb}$ reached baseline level. In six patients the postauricular reflex was larger than $2 \mu \mathrm{V}$ (maximum $8.7 \mu \mathrm{V}$ ).

During the final measurement RECOVERY, when the patients opened their eyes spontaneously, the latencies $\mathrm{Na}$ and $\mathrm{Nb}$ were still prolonged $(P<0.05)$. Eight patients presented a large postauricular reflex $(>3.5 \mu \mathrm{V}$, maximum $8.9 \mu \mathrm{V}$ ). However, only five of these patients had shown a PAR larger than $1.5 \mu \mathrm{V}$ at AWAKE. Figure 3 demonstrates the change of the $\mathrm{Nb}$ latencies for all patients during the different measurements.

\section{$P_{K}$ values of prediction probability were as follows for the latency components}

$\mathrm{Na}-0.68, \mathrm{~Pa}-0.64, \mathrm{Nb}-0.7 \mathrm{l}$; for the amplitudes respectively: $\mathrm{NaPa}-0.71, \mathrm{PaNb}-0.57 .9$ Therefore, with respect to the decreasing anesthetic depth during recovery, the latency $\mathrm{Nb}$ and the amplitude $\mathrm{PaNa}$ were the best predictors. 
TABLE I MLAEP-latency components

\begin{tabular}{llllr}
\hline & AWAKE & ANESTH & PRE-EXT & POST-EXT \\
\hline $\mathrm{Na}$ & $17.6 \pm 1.3$ & $28.5 \pm 5.6^{*}$ & $19.0 \pm 1.4^{*}$ & $18.5 \pm 1.8^{*}$ \\
$\mathrm{~Pa}$ & $29.8 \pm 4.8$ & $37.8 \pm 7.6$ & $32.9 \pm 2.6^{*}$ & $30.3 \pm 4.2$ \\
$\mathrm{Nb}$ & $44.7 \pm 7.8$ & $63.5 \pm 14.3^{*}$ & $54.9 \pm 5.5^{*}$ & $48.5 \pm 8.5$ \\
\hline
\end{tabular}

Means \pm SD of midlatency auditory evoked potential (MLAEP) waveforms $\mathrm{Na}, \mathrm{Pa}$ and $\mathrm{Nb}$ in the awake state, during 1 MAC isoflurane anesthesia and during emergence from anesthesia (pre-extubation, postextubation and $38 \pm 12$ min after stopping isoflurane). $n=22$ patients. ${ }^{*} P<0.05 v s$ AWAKE by paired t test (see text for more details).

TABLE II MLAEP amplitude components

\begin{tabular}{llllll}
\hline & AWAKE & ANESTH & PRE-EXT & POST-EXT & RECOVERY \\
\hline $\mathrm{NaPa}$ & $2.4(11.7)$ & $0.7(2.6)$ & $0.8(1.5)^{*}$ & $2.3(7.7)$ & $2.7(10.7)$ \\
$\mathrm{PaNb}$ & $1.0(2.5)$ & $0.6(0.7)$ & $0.9(1.1)$ & $1.1(3.9)$ & $1.3(4.6)$ \\
\hline
\end{tabular}

Midlatency auditory evoked potential (MLAEP) amplitudes (median and ranges) during 1 MAC isoflurane anesthesia and during emergence from anesthesia (pre-extubation, postextubation and recovery $[38 \pm 12 \mathrm{~min}$ after stopping isoflurane $]$ ). $n=22$ patients. ${ }^{*} P<0.05 \mathrm{vs}$ AWAKE by Wilcoxon's test (see text for more details).

TABLE III Clinical variables

\begin{tabular}{|c|c|c|c|c|c|}
\hline & $A W A K E$ & ANESTH & PRE-EXT & POST-EXT & RECOVERT \\
\hline Heart rate (beats. $\mathrm{min}^{-1}$ ) & $67 \pm 9$ & $71 \pm 9$ & $65 \pm 13$ & $79 \pm 12^{*}$ & $81 \pm 15^{*}$ \\
\hline $\mathrm{MAP}(\mathrm{mmHg})$ & $101 \pm 10$ & $78 \pm 9^{*}$ & $97 \pm 11$ & $100 \pm 10$ & $101 \pm 9$ \\
\hline $\mathrm{SaO}_{2}(\%)$ & $98 \pm 1$ & $99 \pm 1$ & $99 \pm 1$ & $99 \pm 1$ & $99 \pm 1$ \\
\hline $\mathrm{PetCO}_{2}(\mathrm{mmHg})$ & & $36 \pm 2$ & $39 \pm 3$ & $45 \pm 7$ & $43 \pm 4$ \\
\hline Temperature (rectal; $\left.{ }^{\circ} \mathrm{C}\right)$ & $36.3 \pm 0.5$ & $36.1 \pm 0.5$ & $36.2 \pm 0.5$ & $36.2 \pm 0.5$ & $36.2 \pm 0.5$ \\
\hline Pet isoflurane $(\%)$ & & $1.1 \pm 0.02$ & $0.3 \pm 0.08$ & $0.2 \pm 0.05$ & $0.1 \pm 0.04$ \\
\hline
\end{tabular}

Means \pm SD of the clinical variables at the awake state, during $1 \mathrm{MAC}$ isoflurane anesthesia and during emergence from anesthesia (preextubation, postextubation and $38 \pm 12 \mathrm{~min}$ after stopping isoflurane). $n=22$ patients; ${ }^{*} P<0.05 v s$ AWAKE by paired t test; MAP $=$ mean arterial pressure.

\section{MLAEP and the postauricular reflex}

Correlation was significant between PAR amplitude and MLAEP amplitude $\mathrm{NaPa}(P<0.001)$ and between PAR latency and MLAEP latency $\mathrm{Na}(P \leq$ $0.042)$ at all measurements. While MLAEP latency $\mathrm{Nb}$ was not correlated with PAR latency at any time, the latency $\mathrm{Pa}$ showed a significant correlation at RECOVERY only $(P=0.003)$. In order to identify a difference between MLAEP waves of patients with a small or a large PAR the patients were divided into two groups: Group I included patients with a PAR amplitude $<2 \mu \mathrm{V}$ (at AWAKE); Group II patients with a PAR amplitude $>2 \mu \mathrm{V}$. With respect to the MLAEP latencies the multivariate analysis revealed an overall significant difference between the different measurements for Group I only $(P=0.009$, Group II: $P=$ $0.150)$ The Friedman test revealed significant changes comparing the different measurements for the amplitudes NaPa for both groups (Group I: $P=0.002$; Group II: $P=0.01$ ).

\section{Vital parameter and clinical findings}

Data of seven female and 15 male patients (age $38 \pm 9$ yr; height $1.77 \pm 0.10 \mathrm{~m}$; weight $75 \pm 13 \mathrm{~kg}$, ASA I-II) were collected. The mean duration of anesthesia was $100 \pm 28 \mathrm{~min}$, while the surgical procedure took $52 \pm 26 \mathrm{~min}$. For induction of anesthesia the patients received $31 \pm 7 \mu \mathrm{g}$ of sufentanil. Additionally $5 \pm 4 \mu \mathrm{g}$ sufentanil were administered $71 \pm 25 \mathrm{~min}$ before the end of anesthesia. The mean time for extubation was $24 \pm 12 \mathrm{~min}$ after the end of anesthesia. The average time between interruption of isoflurane and spontaneous eye opening was $38 \pm 12 \mathrm{~min}$. Patients did not require any additional medications either for stabilizing hemodynamics or against pain or nausea during the study period.

Table III summarises the significant changes for the vital signs. The changes in MLAEP variables were significantly correlated with the isoflurane concentration $(P \leq 0.004)$. The differences in isoflurane concentration reached statistical significance among all measurements (paired t test: $P \leq 0.004$ ). There was no 
correlation between the sufentanil dose per weight and total time of anesthesia and any of the MLAEP variables. The changes in MLAEP latencies were correlated with the changes of mean arterial pressure $(P<$ $0.001)$, while $\mathrm{Nb}$ only correlated with heart rate changes $(P=0.004)$.

During the interview at the first postoperative day 13 patients did not remember anything of the recovery period, while nine patients indicated memory (two patients remembered the auditory cliques, seven patients the shown object). There was no difference in any of the MLAEP parameters at any time between patients with and without explicit memory.

\section{Discussion}

In comparison to the awake state we could demonstrate profound changes of MLAEP components, which were, in part, reversed during recovery from anesthesia. In most patients the MLAEP components were completely suppressed. In all other patients the latencies were significantly prolonged. During emergence, the MLAEP components reappeared. The latencies gradually decreased and the amplitudes increased in relation to the decreasing anesthetic isoflurane concentration. However, when the patients were responsive again, the latencies $\mathrm{Na}$ and $\mathrm{Nb}$ were still prolonged, indicating impairment in processing of the auditory signal.

While the group effect was strongly significant, the individual MLAEP responses differed markedly, expressing a large inter- and intra-individual variation. We could document that at AWAKE and during RECOVERY the MLAEP variable $\mathrm{Na}$ was correlated with the PAR. However, patients with a large PAR response during AWAKE did not always present a large PAR during RECOVERY. Therefore there does not seem to be a linear recovery profile of the PAR in all patients. When interpreting our results for the patients with and without a large PAR, it must be taken into account that the statistical power was low due to the small number of patients in the two groups. In order to elucidate the relationship between PAR and MLAEP components during light stages of anesthesia a larger population should be investigated, combining MLAEP monitoring with electromyography. Different stimulation and recording modalities like lower stimulation intensity or using only one mastoid electrode could help to decrease the PAR response during clinical monitoring. ${ }^{10}$ However, during surgical anesthesia with 1.2 volume \% isoflurane the PAR was completely suppressed in all patients except in one.

Data in AWAKE reported here are in line with prior findings, stating mean values of the $\mathrm{Nb}$ latencies ranging from 36 to $50 \mathrm{msec}(\mathrm{SD} \mathrm{l}-7 \mathrm{msec}) .{ }^{11,12}$ In part, this large variation might be explained by the different techniques used for recording the MLAEP. Often the recording modalities are determined by the equipment used. However, there are no strict guidelines for recording of MLAEP. Inter-individual variation was also reported in subsequent studies, when the same recording techniques were used. Therefore, substantial interindividual differences have to be taken into account.

With respect to the changes of MLAEP waveforms induced during isoflurane anesthesia, our findings corroborate results of previous studies, which documented that isoflurane decreases MLAEP amplitudes and increases latencies. ${ }^{13,14}$ In $73 \%$ of our patients the MLAEP components disappeared completely during anesthesia. Similar findings have been documented for enflurane (1.2\%) and sevoflurane (1.5\%). However, for isoflurane it had not been documented precisely before. ${ }^{15,16}$ For patients undergoing cardiac surgery with different anesthetic regimes, Schwender et al. showed that, in patients with implicit memory, the waveform pattern of MLAEPs continued during anesthesia. ${ }^{17}$ In all patients with implicit memory, the latency increase of $\mathrm{Pa}$ was less than $12 \mathrm{msec}$ during anesthesia when auditory information was presented. In contrast, when the latency increase was greater than $12 \mathrm{msec}$ during anesthesia, no case of implicit memory was found. They concluded that if MLAEP are preserved during general anesthesia, auditory information may be processed and indicated, when implicit memory tests are used postoperatively. However, in the present population we could not document a correlation between explicit memory performance and any of the MLAEP components during recovery from anesthesia.

To determine threshold values of MLAEP for prediction of movement during light anesthesia Schwender et al. investigated patients anesthetized with isoflurane or propofol in combination with epidural anesthesia. ${ }^{18} \mathrm{~A}$ threshold of $60 \mathrm{msec}$ of the $\mathrm{Nb}$ latency proved to be most predictive of movement during anesthesia and during recovery from anesthesia. Comparisons with the present study are difficult since our study was not designed to predict movement. Schwender et al. documented $\mathrm{Nb}$ latencies of about $52 \mathrm{msec}$ when spontaneous movement occurred. This fits our data almost perfectly, where the mean $\mathrm{Nb}$ latency was about $55 \mathrm{msec}$ before extubation, when the patients tolerated the endotracheal tube and did not move, and $49 \mathrm{msec}$, immediately after extubation at a time when patients opened their eyes on command. However, in light of our findings, it remains questionable whether defining a general threshold value for individual prediction is a sensible 
endeavour, given the substantial inter-individual variance observed. The low $\mathrm{P}_{\mathrm{K}}$ values in the present study indicate that the prediction of recovery in the individual case is limited by MLAEP components.

Newton et al. studied the relation between MLAEP and simple tests of awareness at subanesthetic isoflurane concentrations $(0.0,0.1,0.2$ and $0.4 \mathrm{MAC})$ in eight anesthesiologist volunteers. ${ }^{19}$ They documented graded changes in MLAEP latencies and amplitudes, which were significantly correlated to the anesthetic concentration. The MLAEP variables were related to the level of response more closely than the end-expiratory gas concentrations. The absolute values of MLAEP data are comparable in our study, yet the changes in MLAEP amplitudes we observed were less sensitive in comparison with those of latencies. Plourde et al. investigated the auditory steady state response (ASSR), a sustained electrical response of the brain to auditory stimuli delivered at fast rates, in ten volunteers. ${ }^{20}$ The ASSR was attenuated in a dosedependent manner (end-tidal isoflurane concentration: $0 \%, 0.26 \%, 0.38 \%, 0.50 \%)$. However, two volunteers had to be excluded in their study due to myogenic potentials, probably from the temporal muscle, contaminating the ASSR.

With respect to the question: "which method is most promising in measuring depth of anesthesia?", MLAEP have been compared to the bispectral index (BIS), a computationally derived parameter of the spontaneous EEG. Gajraj et al. documented that the AEP index was best at distinguishing the transition from unconsciousness to consciousness during sedation with propofol. ${ }^{21}$ In contrast, in a volunteer study the BIS correlated better with sedation scores than the MLAEP. ${ }^{22}$

The present study documented that anesthetic induced changes of MLAEP were, in part, reversed during emergence from isoflurane anesthesia, indicating impairment of auditory signal processing in the CNS. In contrast to the distinct group effects, predictions in individual patients were limited and it was not possible to predict arousal based on population derived values. New methods for analyzing MLAEP during anesthesia have been suggested recently. The AEP-index, derived from the raw AEP signal, or online fast extraction of AEP waveforms (markedly reducing the number of sweeps for averaging), have been advocated to be superior to conventional visual analysis. ${ }^{23,24}$ Further studies are needed to investigate whether these new methods may overcome the limitations in MLAEP interpretation demonstrated in the present study.

\section{References}

1 Kress JP, Pohlman AS, O’Connor MF, Hall JB. Daily interruption of sedative infusions in critically ill patients undergoing mechanical ventilation. $\mathrm{N}$ Engl J Med 2000; 342: 1471-7.

2 Sandin RH, Enlund G, Samuelsson P, Lennmarken C. Awareness during anaesthesia: a prospective case study. Lancet 2000; 355: 707-11.

3 Schneider G, Sebel PS. Monitoring depth of anaesthesia. Eur J Anaesthesiol 1997; 14(Suppl. 15): 21-8.

4 Thornton C, Sharpe RM. Evoked responses in anaesthesia. Br J Anaesth 1998; 81: 771-81.

5 Pockett $S$. Anesthesia and the electrophysiology of auditory consciousness. Conscious Cogn 1999; 8: 45-61.

6 Thornton C, Barrowcliffe MP, Konieczko KM, et al. The auditory evoked response as an indicator of awareness. Br J Anaesth 1989; 63: 113-5.

7 Davies FW, Mantzaridis H, Kenny GNC, Fisher AC. Middle latency auditory evoked potentials during repeated transitions from consciousness to unconsciousness. Anaesthesia 1996; 51: 107-13.

8 Winer BJ. Multifactor experiments having repeated measures on the same elements. In: Winer BJ (Ed.). Statistical Principles in Experimental Design, $2^{\text {nd }}$ ed. New York: McGraw Hill Book Company, 1971: 514-603.

9 Smith WD, Dutton RC, Smith NT. Measuring the performance of anesthetic depth indicators. Anesthesiology 1996; 84: 38-51.

10 Jones JG, Aggarwal S. Monitoring the depth of anaesthesia. In: Ghoneim MM (Ed.). Awareness During Anesthesia. Oxford: Butterworth Heinemann, 2001: 69-91.

$11 \ddot{O} z$ damar Ö, Kraus N. Auditory middle-latency responses in humans. Audiology 1983; 22: 34-49.

12 Picton TW, Hillyard SA, Krausz HI, Galambos R. Human auditory evoked potentials. I: Evaluation of components. Electroencephalogr Clin Neurophysiol 1974; 36: 179-90.

13 Newton DEF, Thornton C, Creagh-Barry P, Dore CJ. Early cortical auditory evoked response in anaesthesia: comparison of the effects of nitrous oxide and isoflurane. Br J Anaesth 1989; 62: 61-5.

14 Heneghan CPH, Thornton C, Navaratnarajah M, Jones $J G$. Effect of isoflurane on the auditory evoked response in man. Br J Anaesth 1987; 59: 277-82.

15 Thornton C, Catley DM, Jordan C, Lehane JR, Royston $D$, Jones JG. Enflurane anaesthesia causes graded changes in the brainstem and early cortical auditory evoked response in man. Br J Anaesth 1983; 55: 479-6.

16 Tatsumi K, Hirai K, Furuya H, Okuda T. Effects of sevoflurane on the middle latency auditory evoked 
response and the electroencephalographic power spectrum. Anesth Analg 1995; 80: 940-3.

17 Schwender D, Kaiser A, Klasing S, Peter K, Pöppel E.

Midlatency auditory evoked potentials and explicit and implicit memory in patients undergoing cardiac surgery. Anesthesiology 1994; 80: 493-501.

18 Schwender D, Daunderer M, Mulzer S, Klasing S, Finsterer $U$, Peter $K$. Midlatency auditory evoked potentials predict movements during anesthesia with isoflurane or propofol. Anesth Analg 1997; 85: 164-73.

19 Newton DEF, Thornton C, Konieczko KM, et al. Auditory evoked response and awareness: a study in volunteers at sub-MAC concentrations of isoflurane. $\mathrm{Br}$ J Anaesth 1992; 69: 122-9.

20 Plourde G, Villemure C, Fiset P, Bonbomme V, Backman $S B$. Effect of isoflurane on the auditory steady- state response and on consciousness in human volunteers. Anesthesiology 1998; 89: 844-51.

21 Gajraj RJ, Doi M, Mantzaridis H, Kenny GNC. Analysis of the EEG bispectrum, auditory evoked potentials and the EEG power spectrum during repeated transitions from consciousness to unconsciousness. Br J Anaesth 1998; 80: 46-52.

22 Iselin-Chaves IA, El Moalem HE, Gan TJ, Jinsberg B, Glass PSA. Changes in the auditory evoked potentials and the bispectral index following propofol or propofol and alfentanil. Anesthesiology 2000; 92: 1300-10.

23 Mantzaridis H, Kenny GNC. Auditory evoked potential index: a quantitative measure of changes in auditory evoked potentials during general anaesthesia. Anaesthesia 1997; 52: 1030-6.

24 Urbonen E, Jensen EW, Lund J. Changes in rapidly extracted auditory evoked potentials during tracheal intubation. Acta Anaesthesiol Scand 2000; 44: 743-8. 